\title{
Correlating Urban Population Density and Sustainability Using the Corona Index Method
}

\author{
Tanushri KAMBLE*1, Sarika BAHADURE1 \\ *Corresponding author \\ ${ }^{1}$ Visvesveraya National Institute of Technology, Department of Architecture and Planning, Nagpur, Maharashtra, INDIA \\ $\triangle$ tanushrikamble@students.vnit.ac.in (D) https://orcid.org/oooo-0oo2-2656-4205 \\ $\triangle$ sarikabahadure@arc.vnit.ac.in (D) https://orcid.org/oooo-ooo1-6281-602X \\ DOI: 10.24193/JSSP.2021.1.03 \\ https://doi.org/10.24193/JSSP.2021.1.03
}

K e y w o r d s: COVID-19, pandemic, sustainability, density, urban areas, India

\begin{abstract}
A B S T RA C T
A high population density is considered beneficial for sustainable urban planning. In crisis conditions, such as the present COVID-19 pandemic, the role of population density needs to be clearly understood in order to deal with the situation and also plan the future pandemic interventions. The paper presents a case study approach in a Nagpur, India to understand the relation between urban population density and the COVID-19 spread during the first wave. Spatial density maps and COVID-19 patient data for five consecutive critical months have been correlated using the corona index method. The corona index helps to determine the severity of the disease spread in neighbourhoods of varying population densities. The study reveals a high corona index in high-density areas and a low corona index in low- and medium-density areas. It shows that although high-density planning is sustainable, it proves hazardous for public health during pandemics. The study reveals that high-density areas are at a greater risk of disease spread during pandemics.
\end{abstract}

\section{INTRODUCTION}

Sustainable development is an integral aspect of the design of future societies (Pirouz et al., 2020). Thus, with sustainability in mind, debates surrounding desirable densities have started worldwide (Boyko and Cooper, 2013). Most of the developed countries have agreed on the 'sustainability-as-density' concept (Quastel et al., 2012). Many researchers have mentioned the benefits of high density for sustainable development in urban areas (Jabareen, 2006; Bramley and Power, 2009; Dempsey, 2012). High density allows proximity to work, access to facilities, encourages mass transport, makes urban areas economically viable, and is conducive to the growth of socially active places.
Countries such as the United States (Muñiz and GarciaLópez, 2019), United Kingdom (Raman, 2010), Australia (Haarhoff et al., 2016) have accepted highdensity planning policies for the sustainable development of their cities. Hence, new policy reforms include measures that involve the compaction and intensification of urban areas, both of which can increase population density, and actions to prevent repercussions on the surrounding environment (Ewing and Cervero, 2010). Such measures safeguard agricultural land, forest land, water resources, and other components by limiting the spread of cities and urban sprawl.

There have been a series of public health emergencies in the past few years (Acuto, 2020). These 
range from SARS in 2003, H1N1 in 2009, Ebola in 2014, to Zika in 2016. Researchers have suggested the adoption of health as the fourth pillar of sustainability (Hakovirta and Denuwara, 2020). The effect of COVID19 on all sustainability pillars needs attention (Gautam and Hens, 2020). Now, COVID-19 has changed the way urban life is seen and has led to the recognition of the need to reform urban areas. There has been evidence of design reforms in homes (Dejtiar, 2020), and offices (Marr, 2020) to deal with the situation. Pandemics will not last, but we should at least be prepared with a built environment that can cause the least damage to humans (Ahlefeldt, 2020). Creating a resilient, sustainable urban environment is thus the preeminent need of today's society.

Developing countries with lack of healthcare facilities are said to be at a high risk. Therefore, it is clear that while high population density is regarded as being sustainable, it works adversely during pandemics such as COVID-19. However, cities across the world differ in their planning. They have different neighbourhood $(\mathrm{NH})$ sizes, street layouts, and climate planning concerns (Karimi, 1998). Hence, drawing parallels may provide absurd results. Developing countries are already struggling to sustain basic services and maintain the existing ones (Kamble and Bahadure, 2019). In such conditions, COVID-19 is a threat to the public health, financial security, and economic sustainability of all developing countries. India has a huge population and a high population density. India has $10 \%$ of the world's urban area and is home to more than one-tenth of the global urban population (Demographia, 2019). Most of the people live in slums and around 90\% of the urban population is involved in the informal sector, as daily wages workers, domestic workers, industrial outworkers, etc. (Naik, 2009). The first case of COVID-19 was reported on January 30, 2020; and 3 other cases on February 03, 2020. The number of cases rose to 25 on March 04 and to 4,778 on April o7 (Reshi et al., 2020). India has confirmed a number of 10,757,610 COVID-19 cases with 154,392 deaths, on February 1, 2020(Government of India, 2020). To counter the spread of the disease, the government took strict measures by sealing international and state borders early. The country was also put under lockdown to curb the spread of the disease from March 25, 2020. This slowed down the growth rate of COVID-19 cases in the country. However, being a developing country, India has had other repercussions from the lockdown. With factories, industries, and other working facilities brought to a standstill, people are facing a huge crisis. Hence, since May 18, 2020, most Indian states have started the procedure of 'unlocking.' Due to these relaxations, there has been a sudden rise in the number of cases.

In the background of the aforementioned issues, the current study aims to investigate the correlation between population density and COVID-19 disease spread in India. The underlying objectives are as follows: 1) to formulate a method for investigation; 2) to apply the method in an Indian urban area to derive meaningful results for urban planning interventions; and 3) to understand weaknesses, and limitations of the method for its improvisation in future. The paper is divided into different sections. Following this section, there is section 2 that explains corona index formulation, and section 3 that explains the methodology; section 4 provides the results, and section 5 discusses the results and concludes the study.

\section{CORONA INDEX FORMULATION}

To devise a method for correlating population density and the COVID-19 spread, it was important to understand certain components involved. The identified components were the scale of investigation and data to be used. Once the components were understood, the corona index equation was formulated. This section explains this process in brief.

\subsection{Scale of investigation}

Some studies have found a correlation between urban population density and the COVID-19 disease spread. The scale of investigations vary from districts (Bhadra et al., 2021), cities and villages (Liu and Su, 2020), to areas within the city i.e., neighbourhoods (Khavarian-Garmsir et al., 2021). Khavarian-Garmsir et al. (2021) advocate that such research should be conducted at a smaller scale to determine if the density of NHs has effects on the COVID-19 spread. Moreover, the $\mathrm{NH}$ is known to be the frontline in the journey towards sustainability (Choguill, 2008). Since the underlying objective of the study is to determine urban sustainability, NH seems to be an appropriate scale to be approached in the analysis.

\subsection{Data for investigation}

The investigation requires data related to density and COVID-19. As far as density is considered, population density is considered by most of the researchers (Liu and Su, 2020; Marchigiani and Vazzoler, 2020; Hamidi et al., 2020; Richiedei and Tira, 2020; Khavarian-Garmsir et al., 2021). Richiedei and Tira (2020) consider density as the 'edge density' that accounts for the degree of compactness or fragmentation of a settlement, while some consider various densities like road density, aged-people density, etc. (Khavarian-Garmsir et al., 2021). In organically developed Indian cities, a single NH may have pockets of various degrees of compactness and fragmentation. Hence, the study utilised NH population density for analysis. Researchers have used COVID-19 data as the 
number of infected people in certain cases (Richiedei and Tira, 2020), or included mortality rates during investigation in other cases (Hamidi et al., 2020). However, the current study considered the number of infected people, since the purpose was to find the relation between population density in the urban areas with the COVID 19 disease spread. While determining the disease spread, another important aspect is the timing of the outbreak (Carozzi et al., 2020). Therefore, the time when the first person was infected in the $\mathrm{NH}$ is crucial and was considered in the study.

\subsection{Calculation of the corona index}

Considering the above-mentioned components, the study proposes to apply a corona index method that helps fulfil the aim of the study (Eq. 1). It calculates the extent of the spread of the disease since the first COVID-19 positive case has been recorded in a particular area. Thus, the corona index conveys the number of measures to be taken in an area. A low index confirms a low spread and a high index confirms a high spread of the disease. The severity of spread in various NHs of the city can thus be compared using their corona indexes.

$$
C I=\frac{N_{c}}{N_{d}}
$$

where:

$C I$ - Corona Index;

$N_{c}$ - number of confirmed COCID-19 patients in a neighborhood;

$N_{d}$ - total number of days counted from first case in a neighborhood.

\section{METHODS}

Using the corona index, the study tries to find the relation between urban population density and COVID-19 disease spread. This section demonstrates the use of the corona index in an Indian urban area.

\subsection{Case identification}

High-density cities such as New York in the United States (Goyal et al., 2020) or London in the United Kingdom (BBC, 2020) have reported a high number of casualties and a high spread of disease due to their high population densities. Currently, India has the highest number of COVID-19 patients in its commercial capital, Mumbai, which has an extremely high population density (19,652 persons per square $\mathrm{km}$, as recorded at 2011 census). These cities have different statuses, some of them being administrative headquarters, or centres of political or commercial importance and may also have varying shares of the migrant workforce, or may be tourist destinations with a varying number of travellers. Such factors may affect the spread of COVID-19 and may mediate the correlation between population density and the disease spread. A similar study by Hamidi (2020) correlates population data from 913 metropolitan areas in the US with COVID-19 disease spread. It finds differing results for metropolitan areas and other cities.

Similar studies conducted during other disease spreads, such as the 1918 influenza (Garrett, 2007; Chowell et al., 2008), show differing or contrasting results. Hence, the study examined a city that is comparable to many other cities in India and in other developing countries and does not hold a status of being state capital, or tourism destination, etc. Therefore, we investigated the city of Nagpur, a tier-2 Indian city. This city was explored in the current study to learn about the relation between the number of COVID-19 cases and the population density. It has a population of 2.4 million individuals and its urban area comprises 217.56 sq $\mathrm{km}$ (square kilometres). It is the geographical centre of India; many industries are developed here, on which the livelihood of thousands of people is dependent; Nagpur represents a major transportation hub (rail and road) having connections with other major metropolitan cities in India.

\subsection{Monthly COVID-19 patient data}

The month wise COVID-19 patient data of Nagpur city shows a high percentage increase in the number of patients in the month of April, and subsequently a drop in the number of infected cases after August (Fig. 1). Hence, the study takes into consideration the data of COVID-19 cases from April 2020 to August 2020, i.e., five consecutive months (or the first COVID-19 wave) for the study.

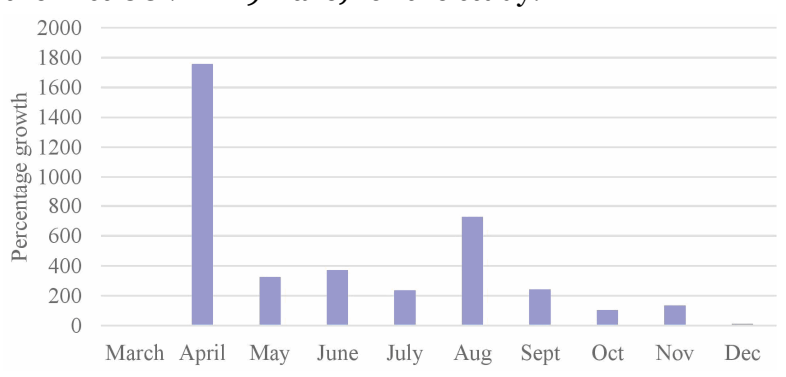
(NMC, 2020).

Fig. 1. Percentage growth of COVID-19 patients

\subsection{Density range}

The urban area of Nagpur has a total of 136 NHs of various population densities. The population density in the city has been recorded to be from as low as 10 persons per hectares (pph) to as high as $1110 \mathrm{pph}$. The first case of COVID-19 in Nagpur was recorded on March 12, 2020. The study considers data of COVID-19 patients for five consecutive months, as taken on April 
30, May 31, June 30, July 31 and August 31. The study uses Eq. 2 to decide the density range for low-, medium-, and high-density NHs. Henceforth, low density refers to $0-130 \mathrm{pph}$, medium density to 131$393 \mathrm{pph}$, whilst high density is considered to be above $393 \mathrm{pph}$.

$D_{r}=D_{a} \pm \frac{D_{a}}{2}$

where:

$$
\begin{aligned}
& D_{r}-\text { high or low density range; } \\
& D_{a} \text { - average neighborhood density. }
\end{aligned}
$$

\subsection{Investigating correlation}

The study uses COVID-19 data obtained from the municipal corporation (NMC, 2020) to calculate the corona index. Corona index is calculated for low, medium, and high density NHs. Further, NH population density and corona index is correlated (using graphs) to fulfill the study objective.

\section{RESULTS}

Figure 2 displays the spatial density map of Nagpur city. It shows the distribution of low, medium, and high density NHs in the urban area. There are about 38 low density NHs (comprising of $27.99 \%$ of the total NHs), 74 medium density NHs (54.41\%), and 24 high density NHs (17.64\%).

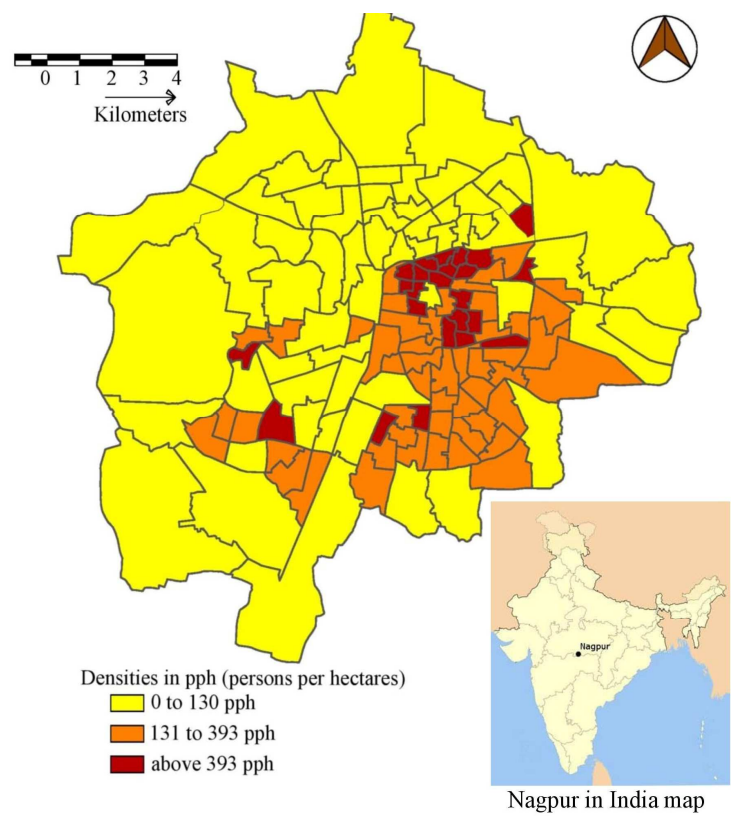

Fig. 2. Spatial density map of Nagpur urban area

Table 1 and Figure 3 display the corona index of various NHs, as of April 30, 2020. The table comprises the data of the corona index value from the highest to the lowest. The X-axis shows NHs arranged from high to low density (Fig. 3). It also mentions the $\mathrm{NH}$ number for clarity. Y-axis shows the corona index in each of the NH. It is observed that high-density areas show a high corona index and low-density areas show a low corona index.

\begin{tabular}{|c|c|c|c|c|c|c|}
\hline NH number & $\begin{array}{c}\text { Density } \\
\text { (pph) } \\
\text { B }\end{array}$ & Density type & $\begin{array}{c}\text { Total } \\
\text { positive } \\
\text { D }\end{array}$ & $\begin{array}{c}\mathbf{1}^{\text {st }} \text { case } \\
\text { Identified } \\
\text { E }\end{array}$ & $\begin{array}{c}\text { Days from } \\
\text { the } 1^{\text {st }} \\
\text { infected } \\
\text { F }\end{array}$ & $\begin{array}{c}\text { Corona } \\
\text { index } \\
G=(D / F)\end{array}$ \\
\hline 52 & 772 & $\mathrm{HD}$ & 74 & $\frac{\mathbf{L}}{\text { Apr-05 }}$ & 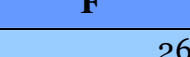 & $\frac{G-(10 / 5)}{28462}$ \\
\hline 67 & 1110 & $\mathrm{HD}$ & $\begin{array}{l}74 \\
19\end{array}$ & Apr-06 & 25 & $\begin{array}{r}2.040 \\
0.76\end{array}$ \\
\hline 57 & 289 & MD & 8 & Apr-18 & 13 & 0.6154 \\
\hline 118 & 225 & MD & 7 & Mar-26 & 36 & 0.1944 \\
\hline 2 & 46 & LD & 5 & Mar-28 & 34 & 0.1471 \\
\hline 22 & 363 & MD & 1 & Apr-21 & 10 & 0.1 \\
\hline 119 & 151 & MD & 2 & Apr-11 & 20 & 0.1 \\
\hline 4 & 53 & LD & 1 & Apr-19 & 12 & 0.0833 \\
\hline 68 & 338 & MD & 1 & Apr-09 & 22 & 0.0455 \\
\hline 87 & 69 & LD & 2 & Mar-12 & 50 & 0.04 \\
\hline 78 & 159 & MD & 1 & Mar-13 & 49 & 0.0204 \\
\hline 86 & 70 & LD & 1 & Mar-13 & 49 & 0.0204 \\
\hline 15 & 152 & MD & 1 & Mar-12 & 50 & 0.02 \\
\hline
\end{tabular}

Table 1. Corona index in Nagpur urban area as on April 30, 2020.

Similar observations were made for other months (Fig. 4-7). An exception or outlier can be observed in June and July graphs (Fig. 5-7). Here, a low-density NH was found to have a high corona index. This is the Central Jail area, and the police officers have been infected owing to direct contact with COVID-19 suspects and patients. The results show that the outbreak of the disease in the city first took place in low- and medium-density areas. However, the disease did not spread much in those NHs, despite the same 
Correlating Urban Population Density and Sustainability Using the Corona Index Method Journal Settlements and Spatial Planning, vol. 12, no. 1 (2021) 25-33

measures taken by the local governments. The patients

much risk to the others in the NH. were quarantined and cured of the disease without

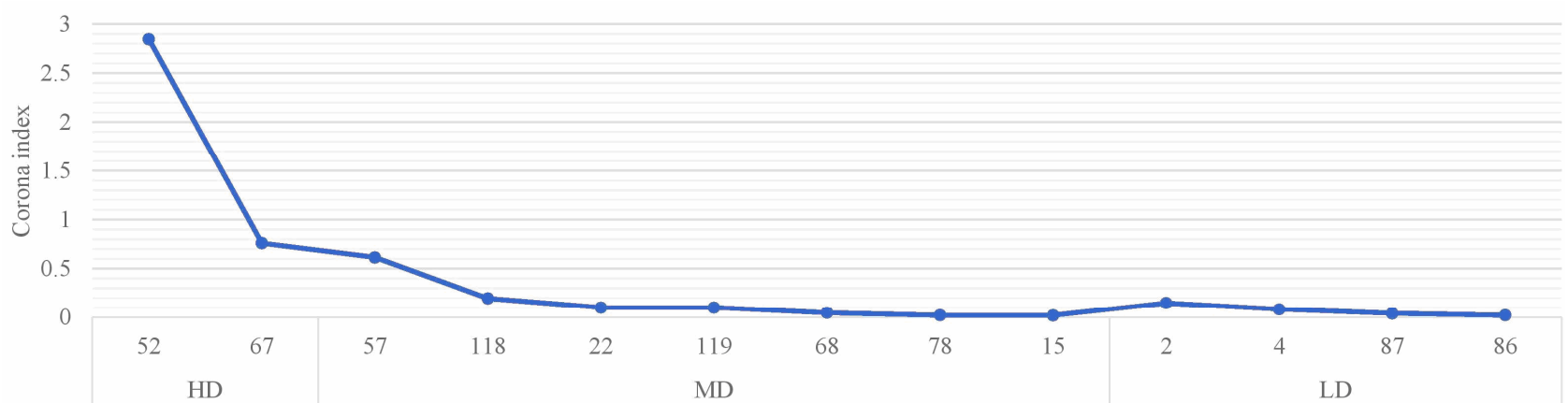

$\mathrm{HD}=$ High-density, $\mathrm{MD}=$ Medium-density, LD=Low-density

Fig. 3. Corona index in Nagpur urban area as on April 30, 2020.

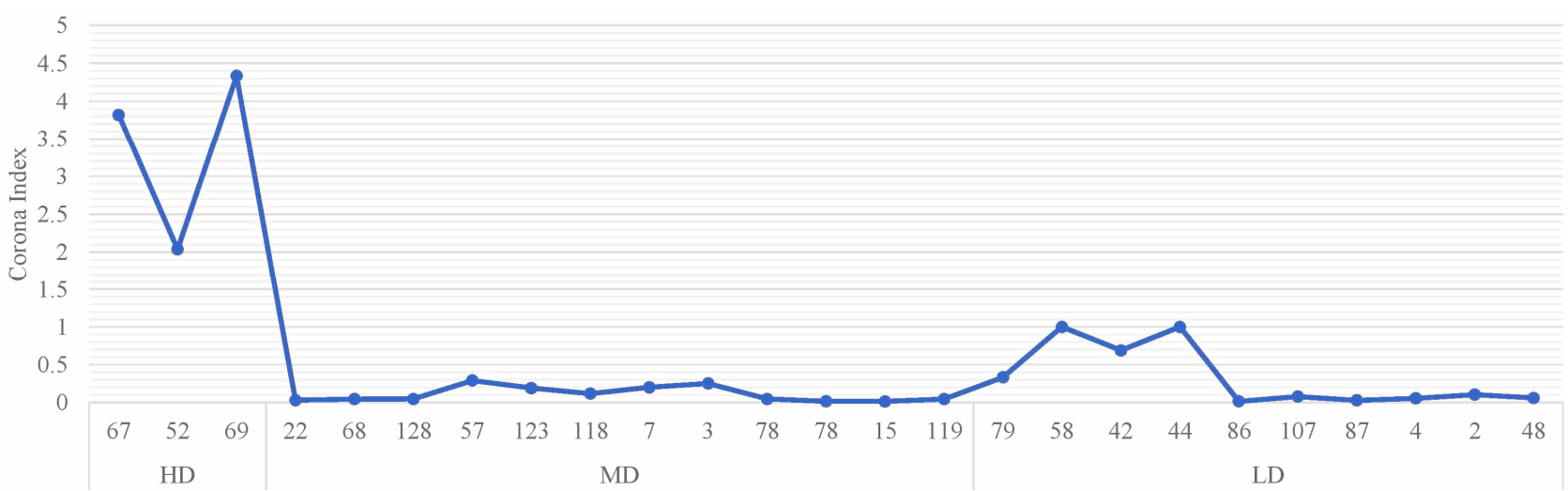

$\mathrm{HD}=$ High-density, $\mathrm{MD}=$ Medium density, $\mathrm{LD}=$ Low-density

Fig. 4. Corona index in Nagpur urban area as on May 31, 2020.

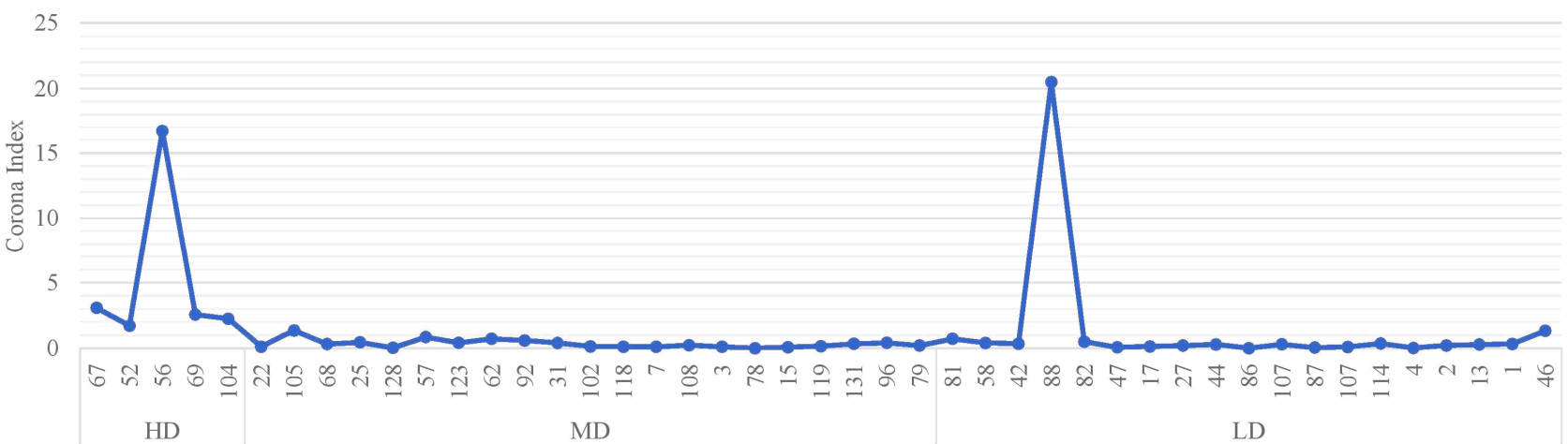

$\mathrm{HD}=$ High-density, $\mathrm{MD}=$ Medium-density, $\mathrm{HD}=$ High-density

Fig. 5. Corona index in Nagpur urban area as on June 30, 2020.

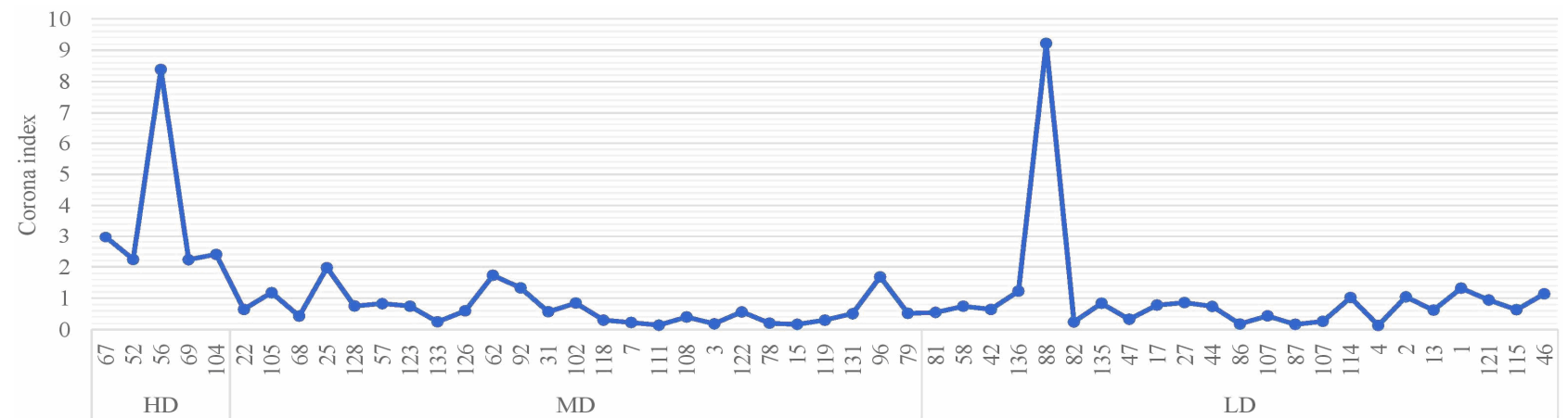

$\mathrm{HD}=$ High-density, $\mathrm{MD}=$ Medium-density, $\mathrm{LD}=$ Low-density

Fig. 6. Corona index in Nagpur urban area as on July 31, 2020. 


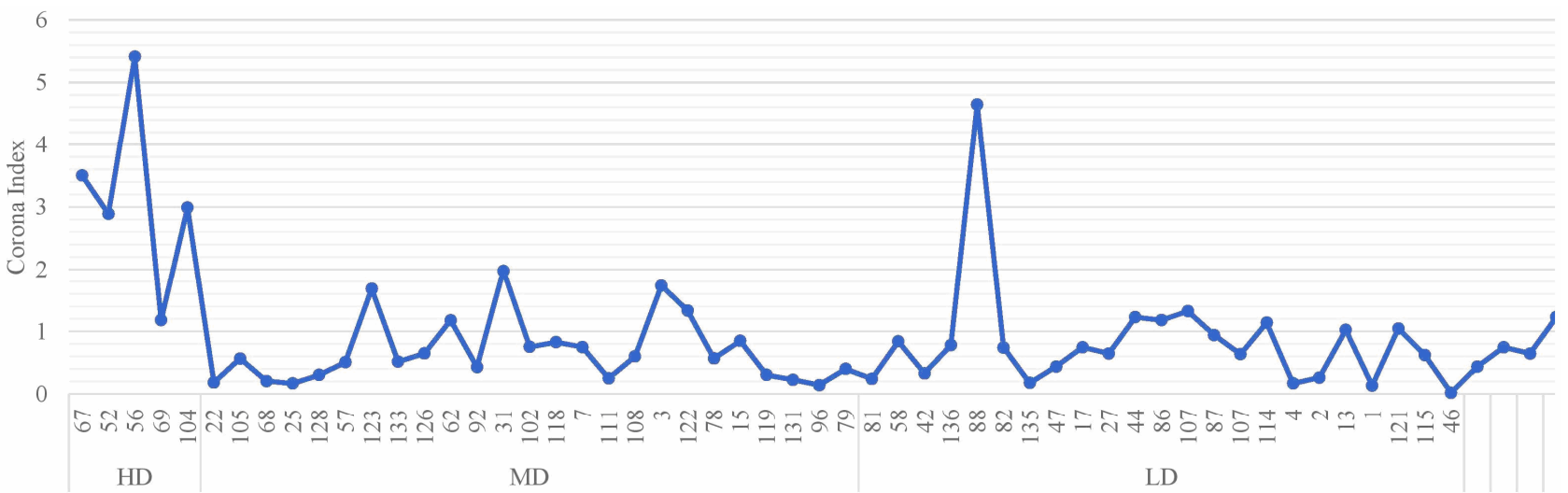

$\mathrm{HD}=$ High-density, MD=Medium-density, LD=Low-density

Fig. 7. Corona index in Nagpur urban area as on August 31, 2020.

In high-density areas, this disease was detected much later. However, a high corona index is observed in these areas. Therefore, high-density areas have a high risk of spreading the infection.

\section{DISCUSSION AND CONCLUSION}

Literature reveals certain methods that establish a relation between population density and COVID-19 disease spread. However, understanding the components of the investigation, the corona index method was designed. It is a simple method that can be replicated easily for further investigations. It is very useful in terms of analysis since it can bring various NHs of different size and density on a comparable scale. This ensures the identification of NHs with high/low disease spread. It also provides a month-wise estimation that can help deriving the trend analysis of the disease spread and for continuous monitoring in pandemics. The results from the corona index method can identify the NHs that are more efficient in reducing the spread. A further study of NHs with a low corona index can provide guidelines for accessibility, connectivity, zoning of facilities, etc. to deal with future pandemics. There have been studies that draw parallels between healthcare and urban planning. The results obtained from the corona index method can help develop sustainable and resilient urban areas by 1) identifying urban areas for rapid pandemic testing, 2) identifying potential disease spreading hotspots in urban areas, 3) identifying areas for relaxation, and 4) trying to reduce the spike in the number of infected cases and pressure on health systems.

The corona index method, however, is still in a primitive stage and has certain weaknesses that may be considered in the future to improve the model. It does not consider access to healthcare facilities in each NHs that may alter the disease spread. Also, the socioeconomic conditions, literacy rates, etc. that may influence the data are not considered. The results may also alter as per the extent to which social distancing and sanitation norms are followed. Furthermore, the 30 identification of the first infected person in a $\mathrm{NH}$ is easier in the first wave, but it might be difficult in subsequent waves.

The study results show that high-density areas have more risk of spreading the disease than the lowand medium-density ones. Cartenì et al. (2020) and Ren et al. (2020) found similar results when investigated the Italian, and Beijing and Guangzhou regions. In the current study, the mixed-use of the NHs and the commercial stores at every corner make NHs vulnerable to physical contact. The ease of accessibility has made NHs more prone to such disease spread. Within the urban areas, high-density NHs have more risk of spreading the disease than low-density areas. Thus, high-density sustainable areas show a reverse equation when it comes to a pandemic situation. One of the strategies to limit the rise of pandemics is rapid testing. Rapid random testing in high-density areas may lower the risk of disease spread before it goes into the state of community spread. The study suggests that urban density has a major role to play during such pandemics. Based on preliminary evidence and empirical investigations, the study suggests that highdensity areas (density above $393 \mathrm{pph}$ ) have a greater risk of spreading COVID-19 disease than medium- and low-density areas.

The identified sustainable goals are environmental, social, and economic development (UN, 2005). High-density planning benefits the environment by limiting population in a defined area and safeguarding resources and nature. It encourages mass transit, thereby reducing pollution and $\mathrm{CO}_{2}$ emission (Dempsey, 2012). Social sustainability is taken care of by social equity and access to social infrastructure (Dave, 2011). Encouraging walking makes NHs socially vibrant and provides healthy living spaces (Raman, 2010). Containment, intensification and compaction are components of 'compact city planning' that promotes high-density planning for sustainable development. Containing growth in a defined area benefits the environment. Intensification and compaction make the fullest use of land as a resource and thus benefit 
economic sustainability. However, in the case of pandemic situations such as COVID-19, these goals seem to work differently. Physical distancing measures, isolation, quarantine, and lockdown have led to socially inactive urban areas. It is said that these conditions will have psychological effects and may even cause longterm effects on the society. The economy, which has been at a standstill due to closures, has caused a decline in the GDPs of all affected nations. The increasing number of COVID-19 cases suggests that current urban planning has failed to fight the disease spread.

Sustainability concerns in urban areas should go beyond carbon emission and climate change. Therefore, certain urban planning interventions should be drafted beforehand. NHs should be made sustainable but adequately able to carry out all the necessary day to day functions. Sustainability goals such as the improvement of food production, skill development, and biodiversity conservation should be integrated with urban planning interventions to have better results. Land use and zoning regulations need to be revised for the allocation of NH facilities. It should be noted that all required facilities are planned in $\mathrm{NHs}$, but an excessive number of them should be avoided. Decentralization of activities in cities may help prevent high density in certain NHs and thus enhance their development. Density may not be an issue, as evident from evidence from medium-density NHs. However, crowding creates problems. Hence, working on optimal density in urban areas is required. The urban population is attracted by infrastructure; hence, infrastructure development should be a priority in all types of NHs.

It is well known that urban planning approaches can help protect urban areas from various ill-effects. The disease spread in high-density areas, however, raises questions on the current assumptions of sustainable planning. This may be a good time to go back to certain utopian planning models or new concepts to deal with the current ongoing crisis to build sustainable and resilient urban areas (Marino and Damiano, 2020). People are going digital, trying to work from home, ordering online goods, and so on, to stay at home. However, meeting people, walking in the $\mathrm{NH}$, and going out are part of healthy psychological and physical life. Post-pandemic urban planning interventions should consider such studies to create a future built environment.

The frequent occurrence of infectious diseases suggests that our cities should be prepared for such disasters today and in the future, as well. This has shown that the present planning is insufficient to counteract the pandemic forces. It is time to make urban NHs resilient to pandemics and self-sustaining since they are the nearest built environment to the public. Even though higher densities are desirable for sustainable development, they may show differing results during pandemics. Hence, an optimal population density should be set, which may safeguard sustainability and provide a better environment to deal with the disease spread. Developing countries with weak healthcare facilities and economies can certainly be in a better position to tackle such situations by monitoring densities in their urban areas.

\section{REFERENCES}

Acuto M. (2020), COVID-19: Lessons for an Urban(izing) World. One Earth, 2(4), 317-319. DOI: https://doi.org/10.1016/j.oneear.2020.04.004

Ahlefeldt F. (2020), Antivirus Architecture as urban design [online], URL:

https://fritsahlefeldt.com/2020/04/28/antivirusarchitecture-as-urban-design/. Accessed on 27.06.2020 BBC (2020), Coronavirus: Which regions have been worst hit? [online]. https://www.bbc.com/news/52282844. Accessed 27.05.2020

Bhadra A., Mukherjee A., Sarkar K. (2021), Impact of population density on Covid-19 infected and mortality rate in India. Modeling Earth Systems and Environment, 7(1), 623-629. DOI:

https://doi.org/10.1007/s40808-020-00984-7

Boyko C. T., Cooper R. (2013), Density and decisionmaking: findings from an online survey. Sustainability, 5(10), 4502-4522. DOI:

https://doi.org/10.3390/su5104502

Bramley G., Power S. (2009), Urban form and social sustainability: the role of density and housing type. Environment and Planning B: Planning and Design, 36(1), 30-48. DOI: https://doi.org/10.1068/b33129

Carozzi F., Provenzano S., Roth S. (2020), Urban Density and Covid-19. CEP Discussion Paper No 1711, DOI: https://cep.lse.ac.uk/pubs/download/dp1711.pdf

Cartenì A., Di Francesco L., Martino M. (2020), How mobility habits influenced the spread of the COVID-19 pandemic: results from the Italian case study. Science of the total environment, 140489, DOI: https://doi.org/10.1016/j.scitotenv.2020.140489

Choguill C. L. (2008), Developing sustainable neighbourhoods. Habitat International, 32.1, 41-48. DOI: https://doi.org/10.1016/j.habitatint.2007.06.007 Chowell G., Bettencourt L. M., Johnson N., Alonso W. J., Viboud C. (2008), The 1918-1919 influenza pandemic in England and Wales: spatial patterns in transmissibility and mortality impact, 501509. DOI: https://doi.org/10.1098/rspb.2007.1477

Dave S. (2011), Neighbourhood Density and Social Sustainability in Cities of Developing Countries. Sustainable Development, 189-205. DOI: https://doi.org/10.1002/sd.433

Dejtiar F. (2020), Is coronavirus pandemic accelerating the digitalization and automation of cities? [online], URL: https://www.archdaily.com/936064/iscoronavirus-pandemicaccelerating-the-digitalizationand-automation-of-cities. Accessed 07.05.2020 
Demographia (2019), Demographia World Urban Areas 15th Annual Edition: 201904. [online], URL: http://demographia.com/db-worldua.pdf. Accessed 20.02.2019

Dempsey N. B. (2012), The key to sustainable urban development in UK cities? The influence of density on social sustainability. Progress in Planning, 77(3), 89141. DOI:

https://doi.org/10.1016/j.progress.2012.01.001

Desai D. (2020), Urban Densities and the Covid-19 Pandemic: Upending the Sustainability Myth of Global Megacities. ORF Occasional Paper, 244(4), 1-4.

Ewing R., Cervero R. (2010), Travel and the built environment: A meta-analysis. Journal of the American planning association, 76(3), 265-294. DOI: https://doi.org/10.1080/01944361003766766

Garrett T. A. (2007), Economic effects of the 1918 influenza pandemic. Federal Reserve Bank of St. Louis, 26. URL: https://www.stlouisfed.org//media/files/pdfs/community-development/researchreports/pandemic_flu_report.pdf

Gautam S., Hens L. (2020), COVID-19: impact by and on the environment, health and economy. Environment, Development and Sustainability. DOI: https://doi.org/10.1007/s10668-020-00818-7

Government of India (2020), India fights corona COVID-19 [online], URL: https://www.mygov.in/covid19. Accessed 1.02.2021

Goyal P., Choi J. J., Pinheiro L. C., Schenck E. J., Chen R., Jabri A., Satlin M. J., Campion T. R., Nahid M., Ringel J. B., Hoffman K. L., Alshak M. N., Li H. A., Wehmeyer G. T., Rajan M, Reshetnyak E., Hupert N., Horn E. M., Martinez F. J., Gulick R. M., Safford, M. M. (2020), Clinical characteristics of Covid-19 in New York city. New England Journal of Medicine, 382(24), 23722374. DOI: 10.1056/NEJMc2010419

Haarhoff E., Beattie L., Dupuis A. (2016), Does higher density housing enhance liveability? Case studies of housing intensification in Auckland. Cogent Social Sciences, 2(1), 1243289. DOI:

https://doi.org/10.1080/23311886.2016.1243289

Hakovirta M., Denuwara N. (2020), How COVID19 redefines the concept of sustainability. Sustainability, 12(9), 3727. DOI:

https://doi.org/10.3390/su12093727

Hamidi S., Sabouri S., Ewing R. (2020), Does density aggravate the COVID-19 pandemic? Early findings and lessons for planners. Journal of the American Planning Association, 86(4), 495-509, DOI: https://doi.org/10.1080/01944363.2020.1777891

Jabareen Y. R. (2006), Sustainable urban forms: Their typologies, models, and concepts. Journal of planning education and research, 26(1), 38-52. DOI: https://doi.org/10.1177/o739456X05285119

Kamble T., Bahadure S. (2020), Neighborhood sustainability assessment in developed and developing countries. Environment, Sustainability, 22(6), Development and https://doi.org/10.1007/s10668-019-00412-6

Karimi K. (1998), Continuity and change in old cities: an analytical investigation of the spatial structure in Iranian and English historic cities before and after modernisation. University of London

Khavarian-Garmsir A. R., Sharifi A., Moradpour N. (2021), Are high-density districts more vulnerable to the COVID-19 pandemic? Sustainable Cities and Society, 70, 102911, DOI: https://doi.org/10.1016/j.scs.2021.102911

Liu S., Su Y. (2020), The impact of the COVID-19 pandemic on the demand for density: Evidence from the U.S. Housing market. Federal Reserve Bank of Dallas. Working papers, DOI: https://www. dallasfed.org//media/documents/research/papers/2020/wp2024r1.pdf Marchigiani E., Vazzoler N. (2020), SLOW Aquileia, during and after the pandemic. UPLanDJournal of Urban Planning, Landscape \& environmental Design, 5(2), 107-126.

DOI: https://doi.org/10.6092/2531-9906/7767

Marino M., Damiano S. (2020), Density and sustainability as a new paradigm for urban resilience. UPLanD-Journal of Urban Planning, Landscape \& environmental Design, 5(1), 69-76; DOI: http://www.upland.unina.it/index.php/upland/article/ download/6995/7949

Marr B. (2020), How the COVID-19 pandemic is fasttracking digital transformation in. [online]. URL: https://www.forbes.com/sites/bernardmarr/2020/o3/ 17/. Accessed 5.04.2020

Muñiz I., Garcia-López M. À. (2019), Urban form and spatial structure as determinants of the ecological footprint of commuting. Transportation Research Part D: Transport and Environment, 67, 334-350. DOI: https://doi.org/10.1016/j.trd.2018.08.006

Naik A. (2009), Informal sector and informal workers in India. Special IARIW-SAIM Conference on Measuring the Informal Economy in Developing Countries, 23-26. URL:

http://citeseerx.ist.psu.edu/viewdoc/download?doi=10 .1.1.625.102\&rep $=$ rep1\&type $=$ pdf

NMC (2020), Official twitter handle. [online] https://mobile.twitter.com/ngpnmc/status/128888158 8323749888. Accessed 03 August 2020

Pirouz B., Shaffiee Haghshenas S., Shaffiee Haghshenas S., Piro P. (2020), Investigating a serious challenge in the sustainable development process: analysis of confirmed cases of COVID-19 (new type of coronavirus) through a binary classification using artificial intelligence and regression analysis. Sustainability, 12(6). DOI:https://doi.org/10.3390/su12062427

Quastel N., Moos M., Lynch N. (2012), Sustainability-as-density and the return of the social: The case of Vancouver, British Columbia. Urban Geography, 1055-1084. 
DOI: http://dx.doi.org/10.2747/0272-3638.33.7.1055.

Raman S. (2010), Designing a liveable compact city: physical forms of city and social life in urban neighbourhoods. Built environment, 36(1), 63-80. DOI: https://doi.org/10.2148/benv.36.1.63

Ren H., Zhao L., Zhang A., Song L., Liao Y., Lu W., Cui C. (2020), Early forecasting of the potential risk zones of COVID-19 in China's megacities. Science of the Total Environment, 729, 138995, DOI: https://doi.org/10.1016/j.scitotenv.2020.138995

Reshi D. A., Showkat A., Rather S. A., Mir M. A. (2020), The Covid-19 Pandemic: A Study of the Current evidEnce in India. UGC care Journal, 31(5), 1-6.
Richiedei A., Tira M. (2020), A first reflection on the correlation between urban density and the spread of COVID-19 in Italy. UPLanD-Journal of Urban Planning, Landscape \& Environmental Design, 5(2), 77-86, DOI: https://doi.org/10.6092/2531-9906/7758

UN (2005), Resolution adopted by the UNGA on 16 September A/RES/6o/1. [online] URL: https://www.un.org/en/development/desa/population /migration/generalassembly/docs/ globalcompact/A_RES_6o_1.pdf. Accessed 15.05.2020 